\title{
OIL-GRADE ALLOY 718 IN OIL FIELD DRILLING APPLICATION
}

\author{
Jing $\mathrm{Xu}^{1}{ }^{1}$, Hendrik John ${ }^{1}$, Gabriela Wiese ${ }^{1}$, Xingbo Liu ${ }^{2,3}$ \\ ${ }^{1}$ Baker Hughes Incorporated, Celle 29221, Germany \\ ${ }^{2}$ West Virginia University, Morgantown, WV 26506, USA \\ ${ }^{3}$ National Energy Technology Laboratory, Morgantown, WV 26507, USA
}

Keywords: Alloy 718, Drilling, Corrosion

\begin{abstract}
Due to continuous advancements in drilling technology, the materials in use have to fulfill higher demands in regards to mechanical properties and corrosion resistance. The complex working loads and high vibration, the hostile downhole environments, together with the high working temperature and pressure encountered when operating in an ultra deep drilling environment, provide major challenges for the drilling tool materials.

This paper focuses on the performance of oil-grade alloy 718 for applications in bottom hole assemblies (BHAs) under drilling conditions. Potentiodynamic polarization was applied to investigate the general characteristics of corrosion and pitting attack. Key influence factors including working temperature, cation species in corrosive medium, and post-mortem heat treatment were discussed. These results will help to direct the optimization strategy of Ni-base superalloys in oil field drilling.
\end{abstract}

\section{Overview Of Oil Grade Alloy 718 in Drilling}

Alloy 718 was invented more than 50 years ago but has been used in the oilfield for drilling tools for approximately the last 20 years. This is related to the fact that the demand for expensive, high strength, corrosion resistant oil grade materials was emerging in the 1990s with the development of expensive modules as part of the bottom hole assembly (BHA). A BHA normally includes modules used for logging while drilling (LWD), and measurement while drilling (MWD). Figure 1 shows the sketch of drill pipe together with the BHA and drill bit.

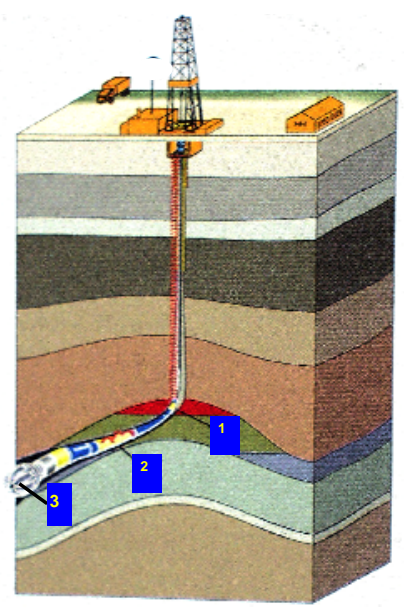

Figure 1 Drill string with 1= drill pipe, 2= bottom hole assembly (BHA), and 3= drill bit 
Compared with other nickel base alloys such as 925 \& 625, alloy 718 is especially interesting in drilling applications for parts of the BHA because of its high strength properties, relatively good corrosion resistance, cost effectiveness and good availability.

During the past 10 years oil field grade alloy 718 variants have been developed which fulfil the minimum requirements regarding strength and microstructural properties as described in API specification 6A 718. The different microstructural requirements for oilfield applications are necessary for drilling operations because of the completely different conditions found in the drilling industry compared with the application conditions found in the aerospace industry when alloy 718 and various heat treatments were developed. The downhole conditions that drilling tools are subjected to include:

- High mechanical loads, with tension, cyclic bending, torsion, vibrations and differential pressure, which are simultaneously acting, shown as figure 2.

- Aqueous drilling fluids with various corrosive substances, including high chloride contents, can lead to pitting, crevice corrosion or stress corrosion cracking (SCC). $\mathrm{pH}$ values can fall below 7 due to the dissolved CO2, hydrogen sulphide and elementary sulphur, which in turn may lead to sulphide induced stress corrosion (SSC).

- The high mechanical loads in combination with the aqueous drilling fluids may cause corrosion fatigue and lead to low fatigue strength values.

- Temperatures are increasing with hole depth / geology and can exceed $150{ }^{\circ} \mathrm{C} / 305^{\circ} \mathrm{F}$. For deep wells temperatures of $250^{\circ} \mathrm{C} / 482^{\circ} \mathrm{F}$ are anticipated, for geothermal applications (hot dry rock) the temperature may rise as high as $300^{\circ} \mathrm{C} / 572^{\circ} \mathrm{F}$. The high temperatures are especially accelerating the corrosion and corrosion fatigue problems. Figure 3 gives an example of BHA control-sub made of alloy 718, which failed due to corrosion fatigue attack.

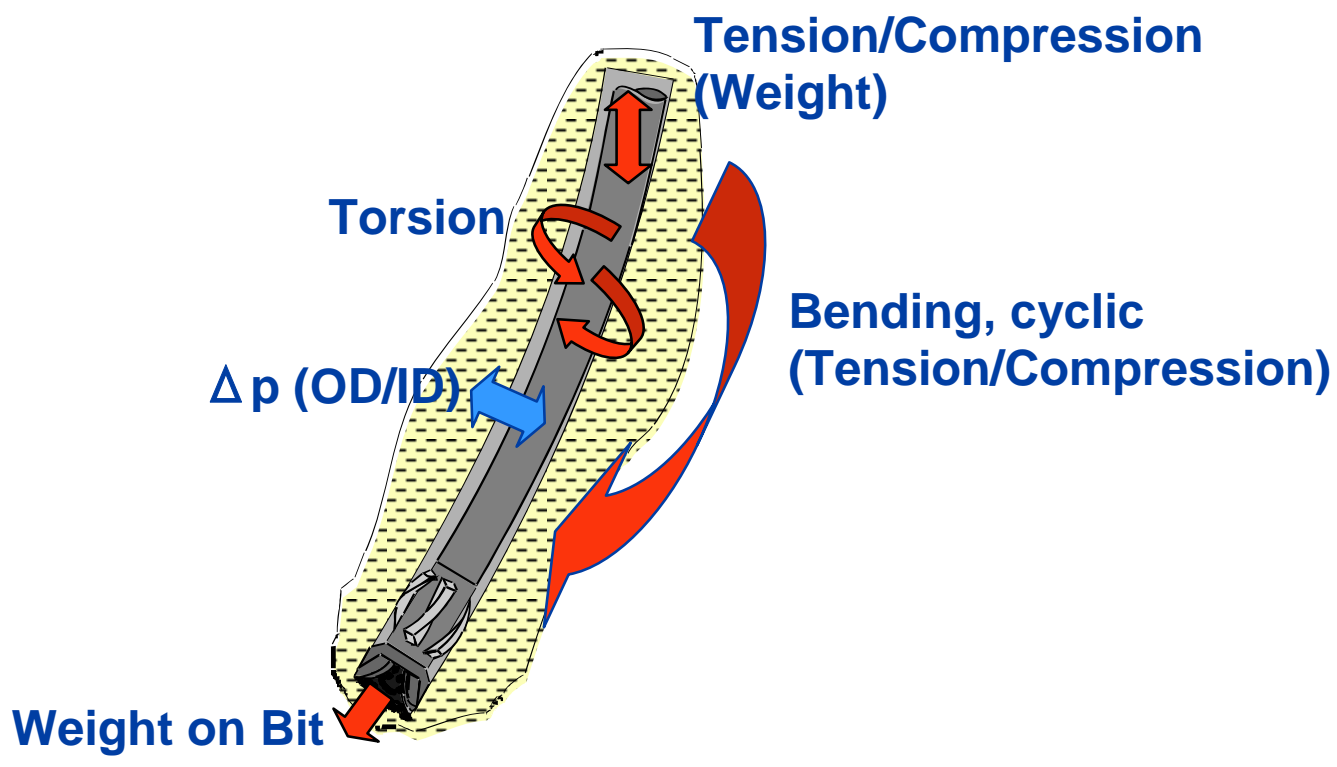

Figure 2 Loading conditions at bottom hole assembly 


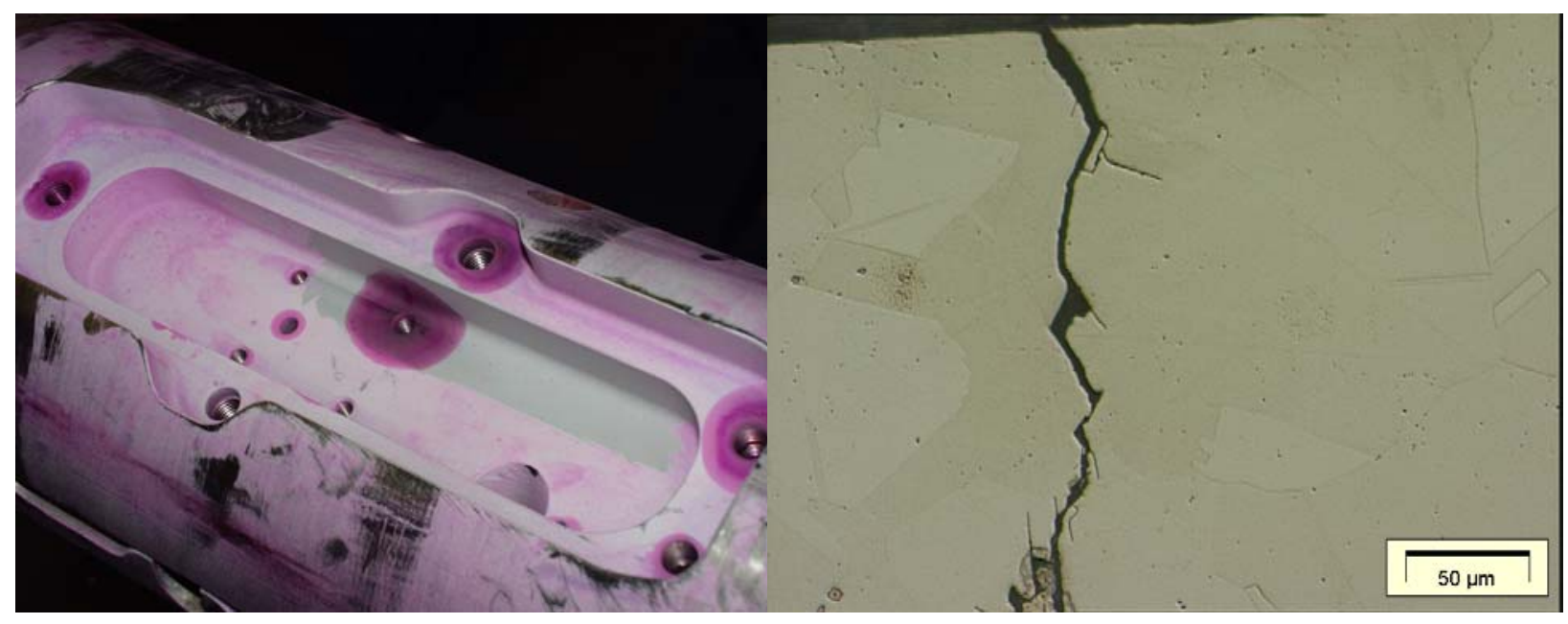

Figure 3 Corrosion Fatigue of Control Sub Made of Alloy 718

The corrosion problems at higher temperatures $\left(>>100^{\circ} \mathrm{C}\right)$ are caused by the increasing electrochemical activity of alloy 718 at higher temperatures, leading to lower pitting potentials, lower SCC and SSC limits, but also very importantly to lower corrosion fatigue strengths. Efforts for better control of the chemical composition, the cleanliness, and the precipitations clearly show a direct effect on the corrosion properties and thus can help to improve the corrosion fatigue strength and expand the design limits of alloy 718.

\section{Microstructure Of Oil Grade Alloy 718}

The microstructure of typical oil-grade alloy 718 is given in Fig. 4(a). The grain size is 4 5 according ASTM E112. Precipitations of ca. $1 \sim 15 \mu \mathrm{m}$, are found scattered around. This type of precipitation usually contains two phases - a titanium nitride phase in the middle with a titanium-niobium carbide phase at the edge, shown in Fig. 4(b). Precipitations of ca. 100 200 $\mathrm{nm}$, which are enriched $\mathrm{Nb}$ and Ta (above $6 \mathrm{wt} . \%$ ), are found along the grain boundaries, as shown in Fig. 4(c)-(d). Delta phase at grain boundary is detrimental to corrosion, SCC, and the corrosion fatigue performance of oil grade alloy 718, and thus is required to be avoided or minimized. Fig. 4(e) shows an unacceptable microstructure due to level of acicular delta phase in grain boundaries [1].

\section{Anti-Corrosion Properties Of Oil Grade Alloy 718}

One of key reasons for the wide application of Alloy 718 in oil and gas industry is due to its good corrosion resistance.

It is reported that alloy 718 is highly resistant to environments that contain carbon dioxide, hydrogen sulfide, and acetic acid. [2] Due to the fact that a large portion of modern hydrocarbon drilling/production takes place in an ocean environment, it becomes critical to study the pitting corrosion on alloy 718 from sea water, mainly sodium chloride, potassium chloride, and calcium chloride. 


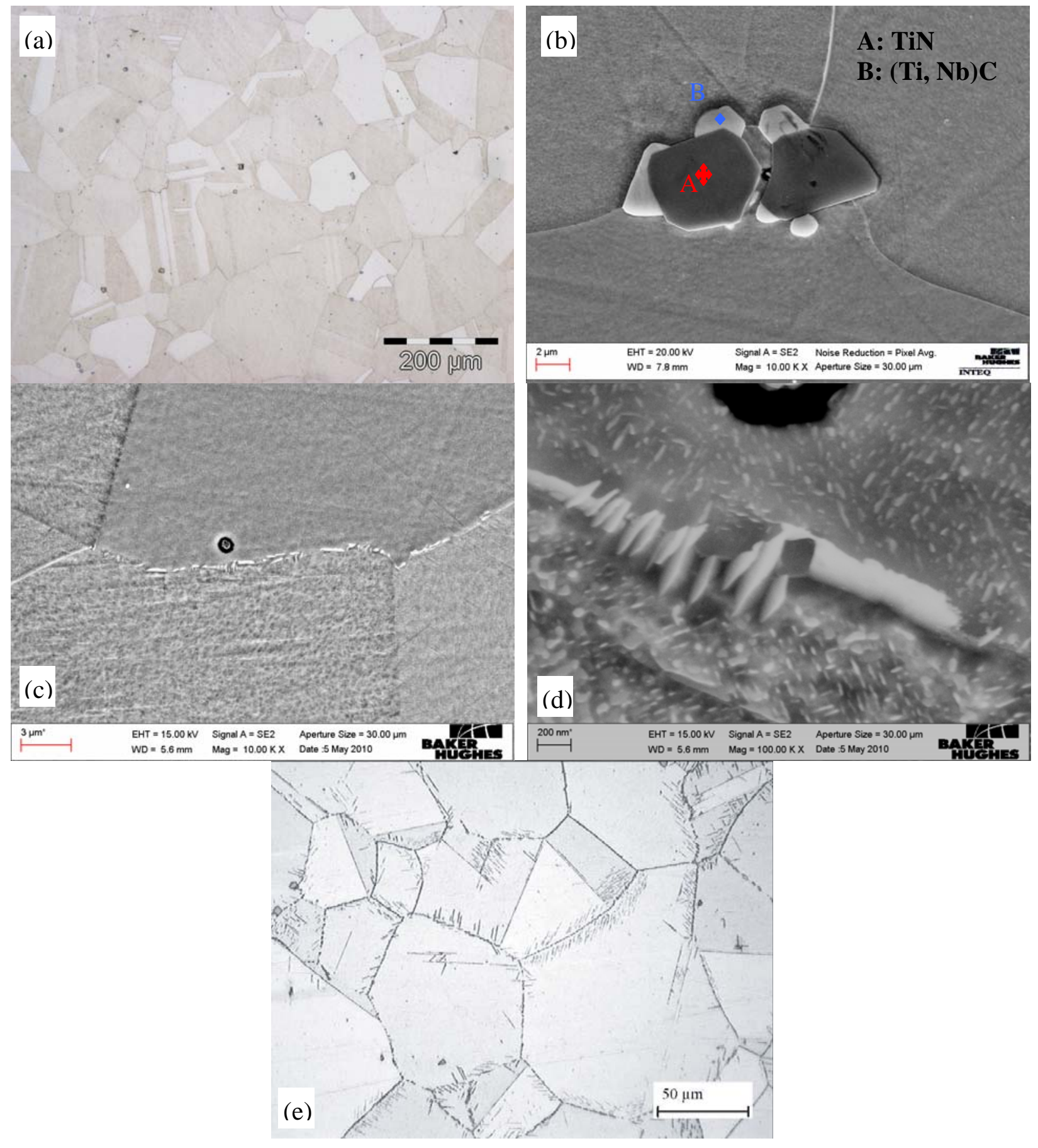

Figure 4 Microstructure of Alloy 718

The value of equilibrium potential, corrosion current density, and pitting potential of alloy 718 in $\mathrm{NaCl}$ solution (80000 ppm $\mathrm{Cl}^{-}$) was summarized in Table 1 and Fig. 5(f). The pitting potential value - Epit -- represents the pitting resistance of alloy 718. It shows from Table 1 that Epit value at $80^{\circ} \mathrm{C}$ is lower than that at $23^{\circ} \mathrm{C}$ and $50^{\circ} \mathrm{C}$. This indicates the increase of temperature reduces the pitting resistance of alloy 718 . 

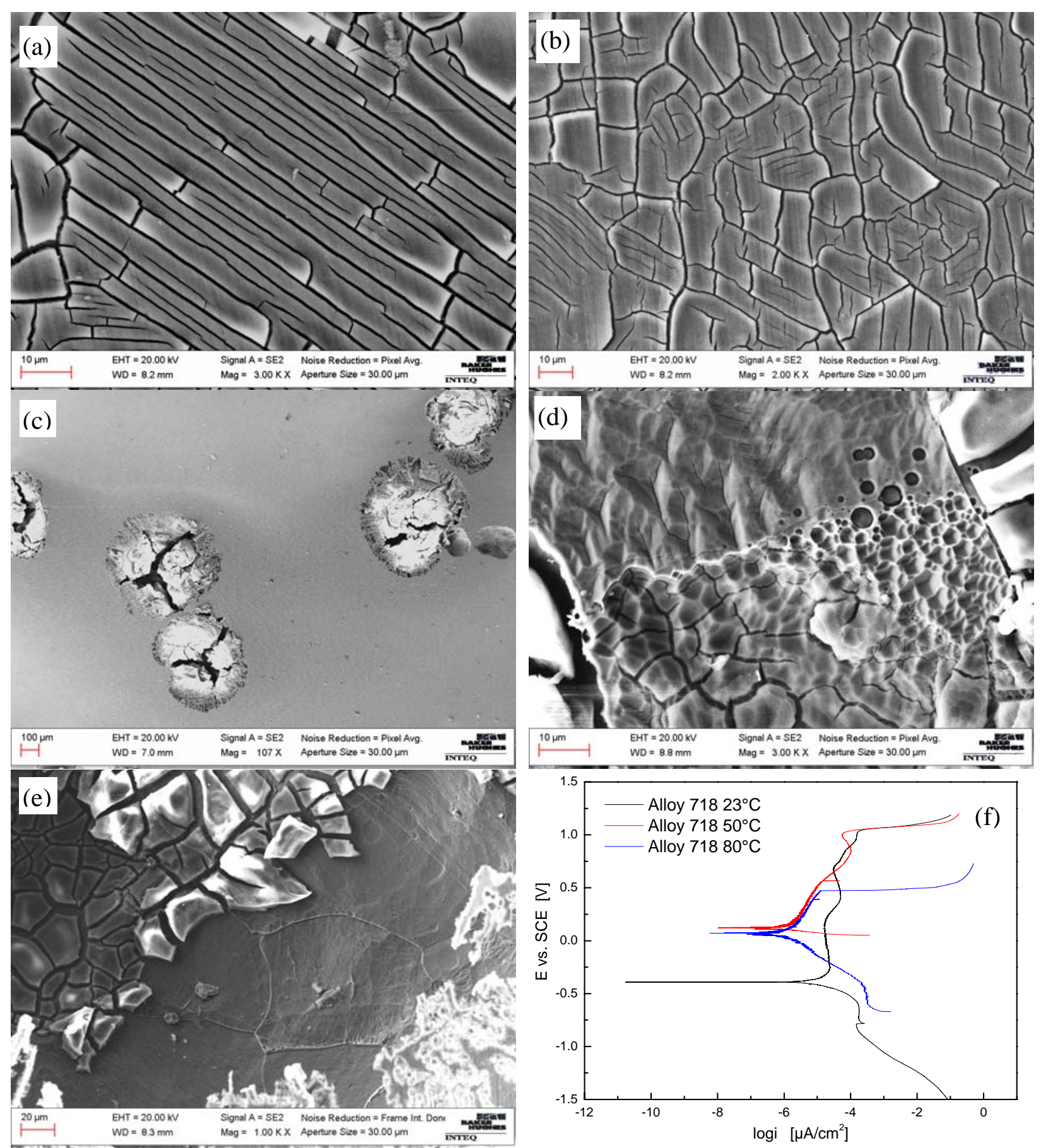

Figure 5 Alloy 718 in High Chloride Containing Solutions at $150^{\circ} \mathrm{C}\left(302^{\circ} \mathrm{F}\right)$ :

(a) $23^{\circ} \mathrm{C}$, (b) $50^{\circ} \mathrm{C}$, (c) - (e) $80^{\circ} \mathrm{C}$. (f) Polarization Curves of Alloy 718 at temperature above.

In general, alloy 718 shows a good pitting resistance against in a high chloride environment at temperatures up to $50^{\circ} \mathrm{C}$, due to the surface passivation. Figs. 5 (a) (b) show the top passive layer on alloy 718 , formed in $\mathrm{NaCl}$ solution $\left(80000 \mathrm{ppm} \mathrm{Cl}^{-}\right)$at $23^{\circ} \mathrm{C}$ and $50^{\circ} \mathrm{C}$. However, the passive layer started dissolving at $80^{\circ} \mathrm{C}$ thus was penetrated by chloride. Fig. 5 (c) indicates that there are a few pits of $400 \mu \mathrm{m} \sim 500 \mu \mathrm{m}$ on alloy 718 surface after $80^{\circ} \mathrm{C}$ polarization corrosion. Some leftover passive products of alloy 718 after $80^{\circ} \mathrm{C}$ polarization was found inside and around pits, indicating passivation phenomena before the self-protective layer was mostly dissolved at $80^{\circ} \mathrm{C}$. Micro-pits size of ca. $3 \mu \mathrm{m}$, shown in Fig. 5 (d), are found inside big pits which are ca. 
$400 \mu \mathrm{m} \sim 500 \mu \mathrm{m}$, hinting that pitting is the accumulation results. Moreover, grain boundary attacking was found after $80^{\circ} \mathrm{C}$ polarization tests, shown in Fig. 5 (e).

Table 1 Corrosion Resistance of Alloy 718 in $\mathrm{NaCl}$ Solution (80000 ppm Cl${ }^{-}$)

\begin{tabular}{|c|c|c|c|}
\hline $\begin{array}{c}\text { Temperature } \\
\left({ }^{\circ} \mathrm{C}\right)\end{array}$ & $\begin{array}{c}\text { Ecorr vs. SCE } \\
(\mathrm{mV})\end{array}$ & $\begin{array}{c}\text { icorr } \\
\left(\mu \mathrm{A} / \mathrm{cm}^{2}\right)\end{array}$ & $\begin{array}{c}\text { Epit vs. SCE } \\
(\mathrm{mV})\end{array}$ \\
\hline \hline $23^{\circ} \mathrm{C}$ & -389 & $4.679 \mathrm{E}-2$ & 1034 \\
\hline $50^{\circ} \mathrm{C}$ & 122 & $2.277 \mathrm{E}-2$ & 1014 \\
\hline $80^{\circ} \mathrm{C}$ & 71 & $3.565 \mathrm{E}-2$ & 473 \\
\hline
\end{tabular}

Table 2 shows open circuit potential and pitting corrosion potential of alloy 718 in high chloride containing solutions at $150^{\circ} \mathrm{C}\left(302^{\circ} \mathrm{F}\right)$. It was found that the critical pitting potentials of alloy 718 in $80000 \mathrm{ppm} \mathrm{Cl}^{-}$solutions at $150^{\circ} \mathrm{C}\left(302^{\circ} \mathrm{F}\right)$ lay between $258 \mathrm{mV}_{\text {SHE }}$ and $347 \mathrm{mV}_{\text {SHE. }}$. The most critical electrolyte for alloy 718 was the $\mathrm{NaCl}$ solution and the less critical the $\mathrm{CaCl}_{2}$ solution. This behavior is different to that of non-magnetic stainless steel. According to the parallel corrosion tests on non-magnetic stainless steel, the experimental results show that the most critical electrolyte for non-magnetic stainless steel was the $\mathrm{CaCl}_{2}$ solution and the less critical the $\mathrm{NaCl}$ solution.

According to the potentiodynamic curves, no repassivation of alloy 718 surfaces was detected. After corrosion tests, alloy 718 surfaces showed some black pits with diameters of $1 \mathrm{~mm}$, shown in Fig. 6.

Another critical finding is that the open circuit potentials of alloy 718 at $150^{\circ} \mathrm{C}\left(302^{\circ} \mathrm{F}\right)$ in the high-chloride containing solutions (up to $225 \mathrm{mV}_{\text {SHE}}$ ) are very close to the critical pitting potentials (from $248 \mathrm{mV}_{\mathrm{SHE}}$ ) and the probability of pitting corrosion increases considerably. This confirms the occurrence of metastable pitting corrosion at OCP on alloy718 under high-chloride containing solutions and high temperature such as $150^{\circ} \mathrm{C}\left(302^{\circ} \mathrm{F}\right)$.
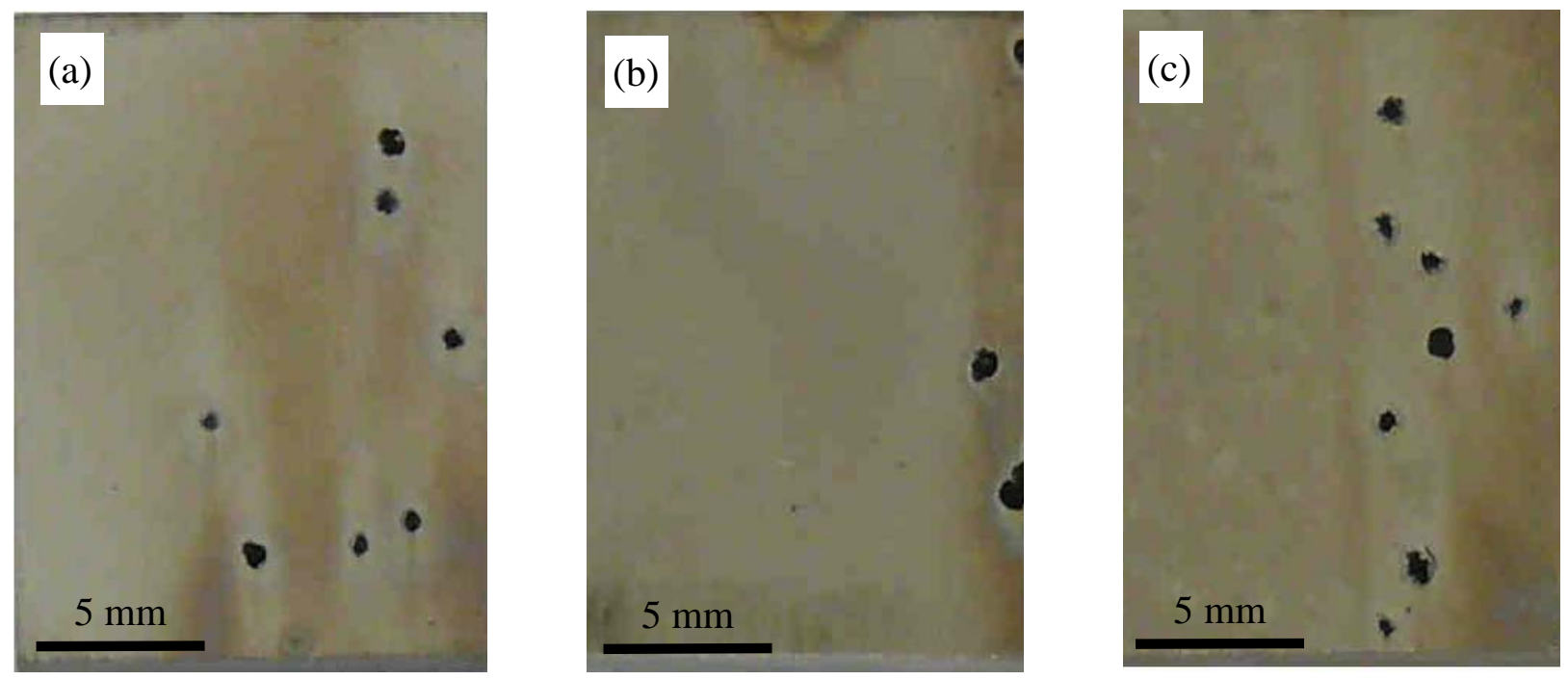

Figure 6 Alloy 718 in High Chloride Containing Solutions at $150^{\circ} \mathrm{C}\left(302^{\circ} \mathrm{F}\right)$ :

(a) $\mathrm{NaCl}$, (b) $\mathrm{KCl}$, (c) $\mathrm{Ca}_{2} \mathrm{Cl}$ 
Table 2 Corrosion Resistance of Alloy 718 in High Chloride Containing Solutions at $150^{\circ} \mathrm{C}\left(302^{\circ} \mathrm{F}\right)$

\begin{tabular}{|c|c|c|c|}
\hline Chloride Solution $\left(\mathrm{Cl}^{-} 80,000 \mathrm{ppm}\right)$ & $\mathrm{NaCl}$ & $\mathrm{KCl}$ & $\mathrm{CaCl}_{2}$ \\
\hline OCP vs. SHE after $150 \mathrm{hrs}[\mathrm{mV}]$ & 145 & 128 & 170 \\
\hline $\mathrm{i}_{\text {OCP }\left[\mu \mathrm{A} / \mathrm{cm}^{2}\right]}$ & 0.0061 & 0.0070 & 0.0041 \\
\hline Epit vs. SHE $[\mathrm{mV}]$ & 258 & 283 & 347 \\
\hline
\end{tabular}

\section{Erosion Of Oil Grade Alloy 718 In Oil Drilling Application}

Another challenge for oil grade alloy 718 is down-hole erosion. In most cases drilling fluids, also known as drilling mud, contains solid particles. The solids content in drilling fluids can be as high as twenty percent. Solid particles, with the assistance of down-hole high pressure, flush on the drilling tool body and can generate erosion at specific areas such as hatch pockets and hatch covers. Moreover, the complicated loading found down-hole, such as the combination of bending/torque and vibrations, could lead to a more intense relative movement and thus accelerate the erosion rate.
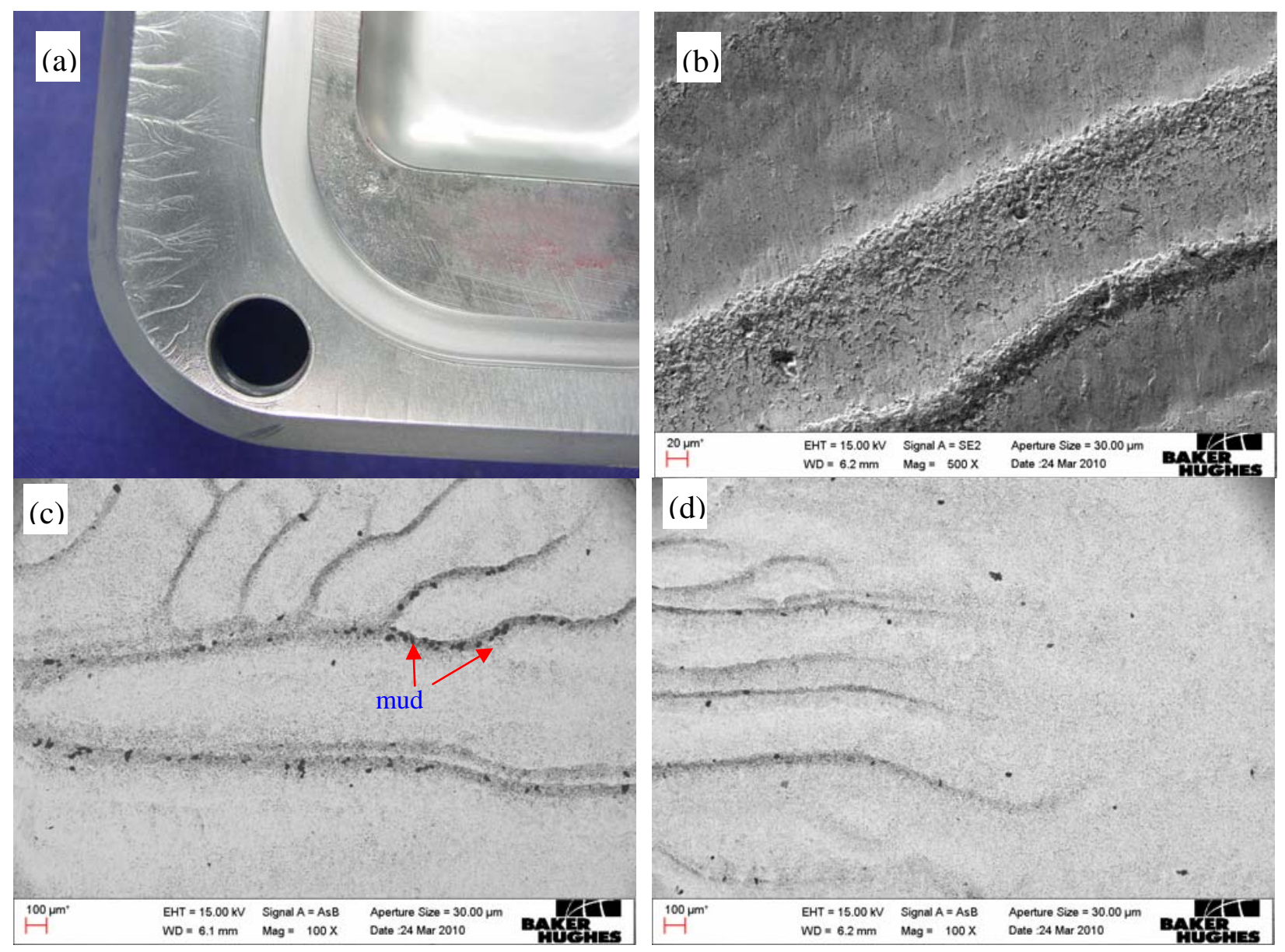

Figure 7 Alloy 718 Hatch Cover after Erosion

(a) hatch cover corner with "leafy tree" erosion pattern; (b) erosion grooves by surface plastic deformation;

(c) - (d) mud particles migration-distribution within erosion grooves. Migration starts at (c) and ends at (d). 
Fig. 7 (a) shows an eroded hatch cover made of alloy 718. Some "leafy tree" pattern was evidently marked on this hatch cover. The erosion is related to the gap conditions (hatch cover/hatch pocket) and the drilling mud, which determine the erosion status to certain extent. The erosion occurred through surface deformation of the bulk solid followed by the loss of small volumes of material. The passage of the erosive causes plastic deformation of the surface which results in the formation of grooves with materials piling up at the groove edges and at the head of the wear track, referred to Fig. 7 (b). After zooming into the impact sites, namely the deep grooves, it reveals that during mud particles--erodent impact, material is deformed and the texture is not as dense as before. Some material was chipped off, due to the high local pressure. The overall eroded surface shows ragged microstructure with small particles loosely piled, illustrated in Fig. 7 (b). In general, erosion response of the alloy depends on the scale of the impact zone relative to the microstructure. For alloy 718, the impact zone encompasses far more than 10 grains, and thus the material response consists mainly of bulk ductile deformation. Mud particles size of $1 \sim 20 \mu \mathrm{m}$ are found inside the erosion grooves, referred to Figs. 7 (c)-(d). Particles distribute from the root of the grooves (edge of the hatch cover); migrating towards the O-ring area and stopping at the narrow-shallow tip of the groove, referred in Figs. 7 (c)-(d).

\section{Heat Treatment Effect Of Oil Grade Alloy 718}
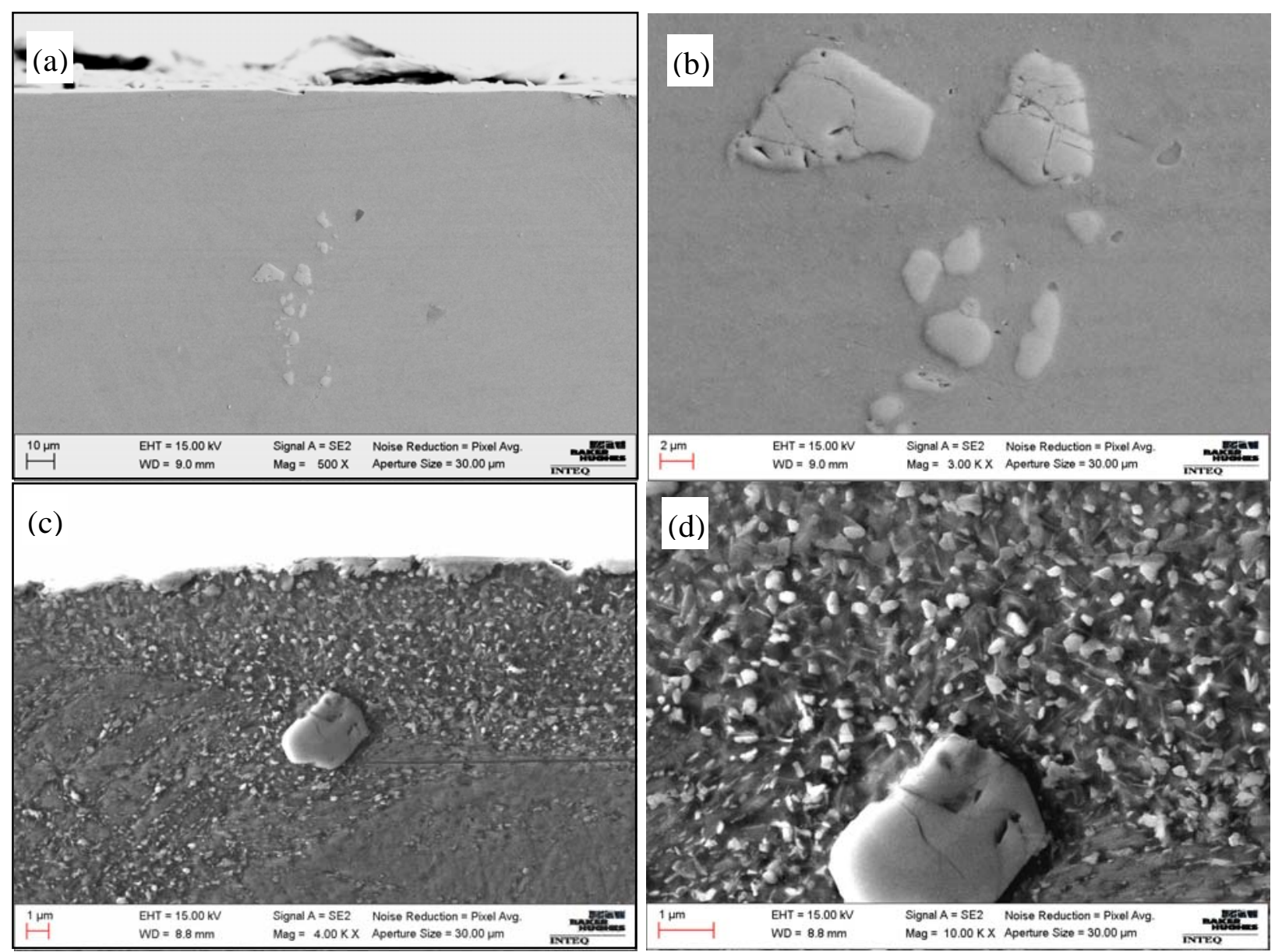

Figure 8 Heat Treatment Effect on Microstructure and Precipitation of Alloy 718

(a)-(b) Before Heat Treatment; (c)-(d) After Heat Treatment 
Since alloy 718 is a precipitation hardening alloy, heat treatment plays an important role in its properties. Fig. 8 shows cross-sectional microstructure and precipitation of Alloy 718 before and after heat treatment.

It indicates, by comparing with Fig. 8 (a) vs (c), Fig. 8 (b) vs (d), that aging assists delta precipitations close to the surface. The precipitates are normally around $100 \mathrm{~nm}$ size, shown in Fig. 8 (c) (d). Precipitations mainly accumulate within $10 \mu \mathrm{m}$ of the surface, shown in Fig. 8 (c).

The effect of heat treatment on the pitting corrosion resistance of alloy 718 is studied in high chloride solution ( $\mathrm{Cl}^{-}$concentration $\left.80,000 \mathrm{ppm}\right)$. Three different aging processes are applied as heatment (i), (ii), and (iii), all of which are popular and currently used as heat treatment standards for oil grade alloy 718 in the oil drilling industry. Fig. 9 shows the polarization curves of alloy 718 when heat-treat of heat (i), (ii), and (iii) is applied. Despite the differences between the three heat treat processes, the corrosion behaviors of alloy 718 at $23^{\circ} \mathrm{C}$ did not change referred to Fig. 9. One explanation for this phenomenon is that the corrosion performance of alloy 718 at low temperature, i.e. up to $50^{\circ} \mathrm{C}$, is determined by its passivation. The properties of the passive layer do not vary with different heat treatments. The other explanation is that the cooling rate difference among these three applied heat treatments is not significant enough to change the corrosion mechanism of the alloy 718 under the corresponding corrosion testing conditions. More study is to be done on this topic in the near future.

Fatigue behaviors of oil grade alloy 718 are studied and the fatigue life of alloy 718 under various heat treatment processes is summarized in Fig. 10. It is found that heat treatment greatly influences the fatigue life of the oil grade alloy 718. The fatigue behaviors can be vary with different aging steps, aging temperature, aging time, and cooling rate. By adjusting the heattreatment on alloy 718, it is expected to improve the microstructure uniformity, accomplish an ideal grain size, and release the internal strength concentration caused during previous machining process. Attention needs to be paid on the grain boundary precipitation during aging. Delta phase at grain boundary is detrimental to corrosion, SCC, and corrosion fatigue performances of oil grade alloy 718 , and thus is required to be minimized during aging.

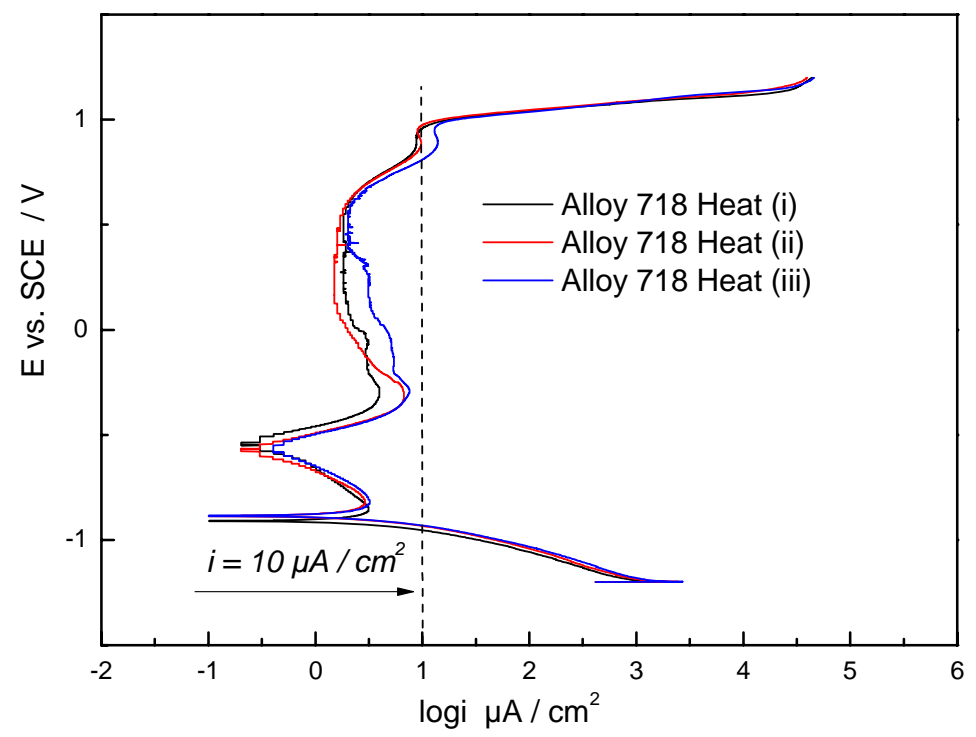

Figure 9 Heat Treatment Effect on Corrosion Behaviors of Alloy 718 


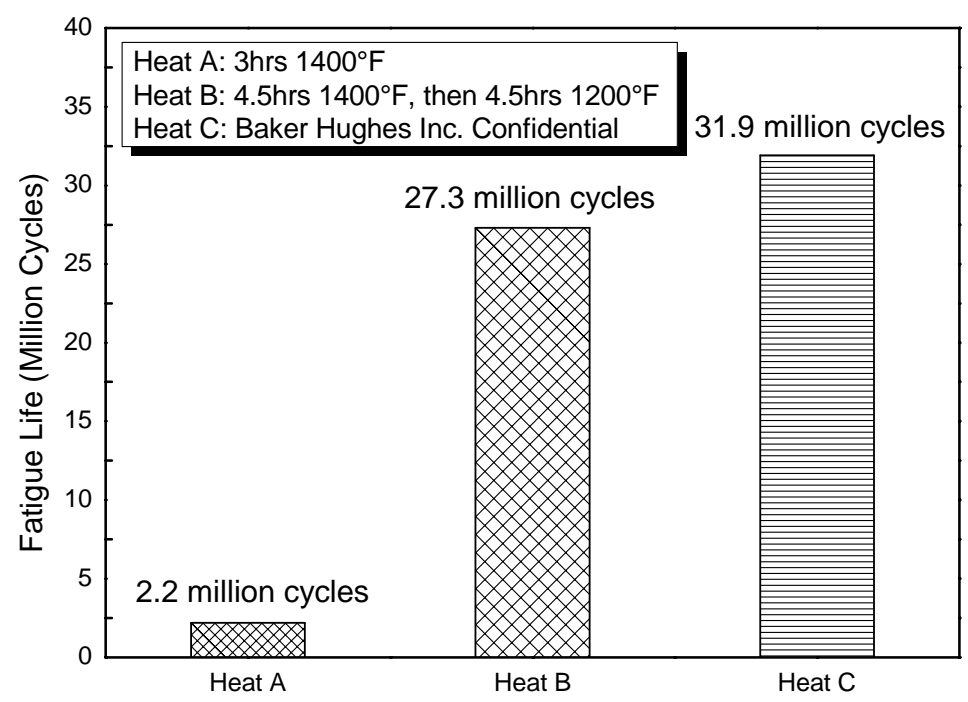

Figure 10 Heat Treatment Effect on Fatigue Life of Alloy 718

\section{Summary}

This paper focuses on the performance of oil-grade alloy 718 for application in bottom hole assemblies (BHAs) under drilling conditions. Discussion is given on microstructure, corrosion, erosion, and heat treatment effect on oil grade alloy 718. These research results will help to direct the optimization strategy of Ni-base superalloys in oil field drilling.

\section{Reference}

$1 \quad$ API specification 6A718: Specification of Nickel Base Alloy 718 (UNS N07718) for Oil and Gas Drilling and Production Equipment. American Petroleum Institute

2 Juri Kolts. Alloy 718 for the oil and gas industry. Superalloy 718-Metallurgy and Applications edited by E.A. Loria, TMS 1989 